\title{
Constructive systems, load-bearing and enclosing structures of high-rise buildings
}

\author{
Elena Anatol'evna Korol' ${ }^{1 *}$, Yuliya Olegovna Kustikova ${ }^{1}$ \\ ${ }^{1}$ Moscow State University of Civil Engineering, Yaroslavskoe shosse, 26, Moscow, 129337, Russia
}

\begin{abstract}
As the height of the building increases, loads on load-carrying structures increase dramatically, and as a result of the development of highrise construction, several structural systems of such buildings have been developed: frame, frame-frame, cross-wall, barrel, box-type, box-to-wall ("pipe in pipe", "Trumpet in the farm"), etc. In turn, the barrel systems have their own versions: cantilever support of the ceilings on the trunk, suspension of the outer part of the overlap to the upper carrying console "hanging house" or its support by means of the walls on the lower bearing cantilever, intermediate position of the supporting cantilevers in height to the floor, from a part of floors. The object of the study are the structural solutions of high-rise buildings. The subject of the study is the layout of structural schemes of high-rise buildings, taking into account the main parameters - altitude (height), natural climatic conditions of construction, materials of structural elements and their physical and mechanical characteristics. The purpose of the study is to identify the features and systematization of structural systems of high-rise buildings and the corresponding structural elements. The results of the research make it possible, at the stage of making design decisions, to establish rational parameters for the correspondence between the structural systems of highrise buildings and their individual elements.
\end{abstract}

\section{Introduction}

High-rise buildings have a specificity, significantly different from them traditional highrise buildings and multi-storey buildings. Among the main features of high-rise buildings are:

- Significant values of both static and dynamic loads on load-bearing structures and on bases;

- high, sometimes critical value of horizontal (primarily wind) loads;

- problems of unevenness of both load values and the nature of their application;

- careful and correct selection of construction materials, excluding separate work of structural elements and ensuring homogeneity of physical and mechanical characteristics;

- Increased significance of natural (airflow, seismicity, temperature, etc.) and technogenic factors (vibration, accidents, fires, local destruction) on the safety of construction and operation;

\footnotetext{
${ }^{*}$ Corresponding author: professorkorol@mail.ru
} 
- complex solutions of internal engineering systems and communications, accompanied by the creation of additional engineering units, which is due to the height of the building;

- Increased requirements for integrated security, including firefighting, involving the use of technical solutions of a qualitatively different level and affecting the choice as volumeplanning, and constructive decisions.

These aspects must be taken into account when choosing a structural scheme of a highrise building and designing load-bearing structures.

The publications devoted to high-rise buildings consider design, construction and operation issues based on unique experience in different countries of the world [1-7]. Despite the fact that this experience is permanently generalized by researchers in this field of construction, the appearance on the world map of each new high-rise building is of interest to a large number of specialists dealing with the problems of developing new building materials, non-traditional structural solutions for load-bearing and enclosing structures (including facades), dealing with issues of hydrogeology, improvement of engineering systems, architects and city planners, construction monitoring services, etc. [8-19].

The unique experience in the world practice of design and construction of high-rise buildings is enriched by new objects every year, taking into account the various conditions for the construction and operation of these buildings and the trends in the development of the society's needs at the present stage in ensuring the quality of living and a comfortable environment of life activity [20-22].

\section{Constructive schemes of height buildings}

The choice of a concrete constructive scheme of a building depends on a complex of factors, the main of which are the height of the building, its purpose, construction conditions (characteristics of foundation grounds, seismicity, atmospheric, especially wind, impacts), architectural and planning requirements.

As the practice of high-rise construction developed in the leading countries, several structural schemes (systems) of the above-ground parts of buildings were developed, tested, improved and implemented:

- frameless with cross-bearing walls,

- frame-frame,

- frame with diaphragms of rigidity,

- barrel, frame-barrel,

- box-type (shell),

- Stem-box ("pipe in the pipe", "trumpet in the farm", "bundle of pipes").

Frameless with a cross-bearing walls scheme (Figure 1a), which for centuries has been the main solution for buildings of any purpose, in high-rise construction is applied sporadically and mainly for residential buildings and hotels, as the space-planning decisions of the buildings for this purpose are completely consistent with the requirements constructive scheme. The unpopularity of frameless wall construction scheme in the environment of architects is explained by limitations of freedom of internal space planning.

The frame-frame structural system (Fig. 1b), which served as the basis for the creation of skyscrapers at the turn of the 19th and 20th centuries, is now widely used in the construction of buildings up to 60 storeys high (in the steel version and later with the reinforced concrete frame). 


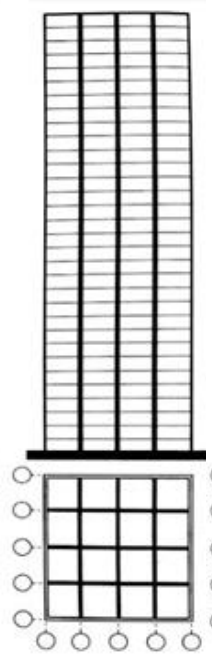

a

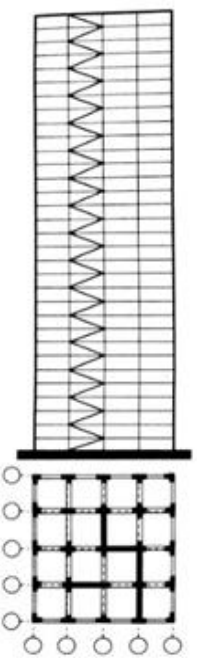

b

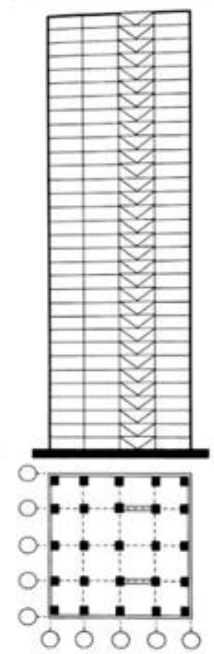

c

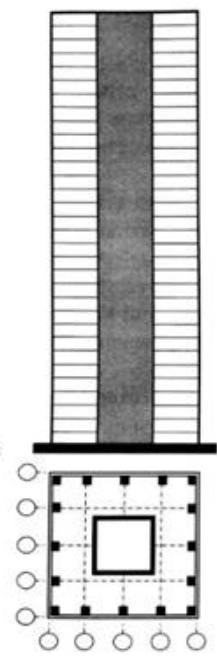

d

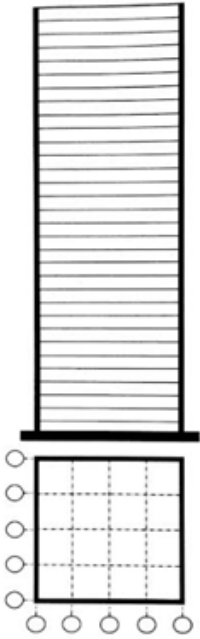

e

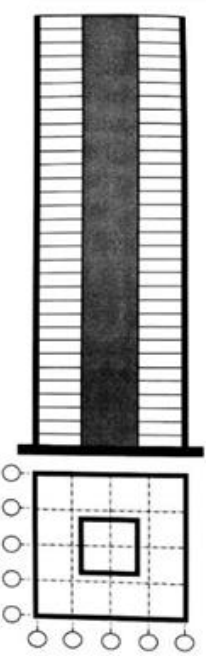

f

Fig. 1. Constructive schemes of high-rise buildings: a) frameless with cross-bearing walls, b) frameframe, c) frame with diaphragms of rigidity, d) barrel, frame-barrel, e) box-shaped (shell) f) stemsbox ("pipe in the pipe," "trumpet in the farm," "bundle of pipes")

However, with the increase in the number of storeys, the inevitable complication of the design of the frame units for the perception of increasing horizontal loads dictates the transition to a bonded frame with through straightened steel vertical stiffening diaphragms or with solid reinforced concrete walls - stiffening diaphragms. In connection with this, a new constructive scheme was proposed-a frame with diaphragms of rigidity (Fig. 1c).

Since the 1960s, new structural systems have been actively embarked on high-rise construction - barrel and shell systems.

The trunked structural system (Figure 1d) as the main supporting structure of the building, which receives loads and impacts, contains a vertical spatial rod - the barrel of rigidity (the "core of rigidity") to the entire height of the building.

In the stiffness of the high-rise building, which is usually located in the central part of the building, a staircase-elevator unit is located, and the structure of the stiffener itself is made of monolithic reinforced concrete, rigid steel structures or a combination thereof. In accordance with European standards, the distance from the outer walls to the core of stiffness in terms of natural light should not exceed $8 \mathrm{~m}$.

The trunk system organically entered the practice of high-rise construction, as it successfully combined with the planning layout of the building. The best conditions for the spatial operation of the structures of the buildings solved according to the barrel scheme provide a strictly central location of the trunk in the plan, as well as the geometric similarity of the shapes of the building and trunk plans with the area of the "core of stiffness" about $20 \%$ of the area of the building plan. The widest distribution in the construction of buildings up to 60 storeys of various purposes (administrative, residential, hotels) was combined framebarrel system (Figure 1d), with the frame location along the outer contour of the building. Joint horizontal movements of the frame and trunk are provided by horizontal outriggersgrillage, located through 18-20 floors. Bearing structures of barrel buildings are mainly reinforced concrete prefabricated and monolithic. The section of the walls of a monolithic trunk varies from $40-100 \mathrm{~cm}$ in the lower floors to $20-30 \mathrm{~cm}$ in the upper ones, depending on the number of storeys.

However, due to the limited dimensions of the staircase-elevator units (trunks) in the buildings of high altitude (more than $200 \mathrm{~m}$ ), this system causes more concentrated loads on 
the base and can not provide the necessary rigidity, in connection with which the world practice has developed a box shell) constructive system, in which the required flexural rigidity is provided by the outer shell of the building. The shell structural system (Figure 1e) is characterized by maximum rigidity in comparison with the above schemes, since the supporting structures are located along the outer contour.

The main shell system is accompanied by two combined shell-barrel ("pipe in the pipe") (Figure 1f) and shell-diaphragm ("bundle of pipes").

As in the main system - shell, and in the combined - sheath-barrel in the center of the plan, the trunk is located with elevator shafts and halls located in its space.

The difference between these variants lies in the horizontal load distribution provided by the project: only on the shell (with the trunk only working on vertical loads from the overlaps) or on the shell and barrel. In the latter variant, the mass of the structure of the floors increases due to their inclusion in the work on horizontal impacts. Nevertheless, most of the shell-type high-rise buildings are built on a shell-and-barrel system, although individual objects have a shell structural system.

The individual specific task of designing shell buildings was the design of a bearing outer shell, combining the bearing and enclosing functions.

Over the past decades, a number of designs have been implemented:

- Spatial bezraaskasnaya multi-storey and multi-span lattice with a frequent step of the columns and floor bolts-crosspieces;

- spatial lattice macro-farm of a large module, whose braces span 10-15 floors, with a rare step of columns;

- Spatial bezraaskasnaya lattice, the rigidity of which increases the dull filling of diagonally located openings;

- lattices of diagonal rods;

- lattices of diagonal and horizontal rods;

- lattices of orthogonal and diagonal rods.

With a further increase in the height of the building, the rigidity of the shell constructions considered may not be sufficient. To this end, in projects that have not been implemented to date, it has been proposed to construct shells from cross-bar structures with the same design of horizontal outriggers-grillage. A means of increasing the hardness of the shell can also serve as a transition from the shell to the shell-diaphragm construction ("bundle of pipes").

The construction of the shell is carried out both from steel elements and from reinforced concrete. Reinforced concrete casings were made monolithic or prefabricated, with preference given to lightweight structural concrete, which made it possible to combine the load-bearing and heat-insulating functions of the wall. In recent years, shells in Europe are made predominantly monolithic from heavy concrete with subsequent insulation and external lining. For elements of steel shells, the most commonly used are rolled or welded elements of closed rectangular cross-section also with subsequent insulation and lining. At the same time, these systems do not allow the use of plastic facade solutions and require the frequent placement of load-bearing racks along the perimeter of the building.

\section{Constructive solutions of the foundations}

The effectiveness of the technical solution of the foundation of a high-rise building increases significantly when it is buried. The depth of foundations can be $15-25 \mathrm{~m}$, and in some cases $-50 \mathrm{~m}$.

At present, in the design and construction of high-rise buildings, three types of foundations have become widely used: pile, plate and pile-plate (Table 1). 
Table 1. Types of foundations widely used in the design and construction of high-rise buildings

\begin{tabular}{|l|l|}
\hline \multicolumn{1}{|c|}{ Characteristic } \\
\hline a) Pile foundation
\end{tabular}

Pile foundation is the most expensive type, however its application, as practice of building and operation of buildings shows, allows to minimize sediment values.

Plate foundation for sand and gravel grounds is most economical if the load is transferred without significant eccentricities

In some cases, pile-plate foundations are the most reliable and economical.

The choice of a rational design and technological solution and the design of the foundations of high-rise buildings is the following process (Fig.2). 


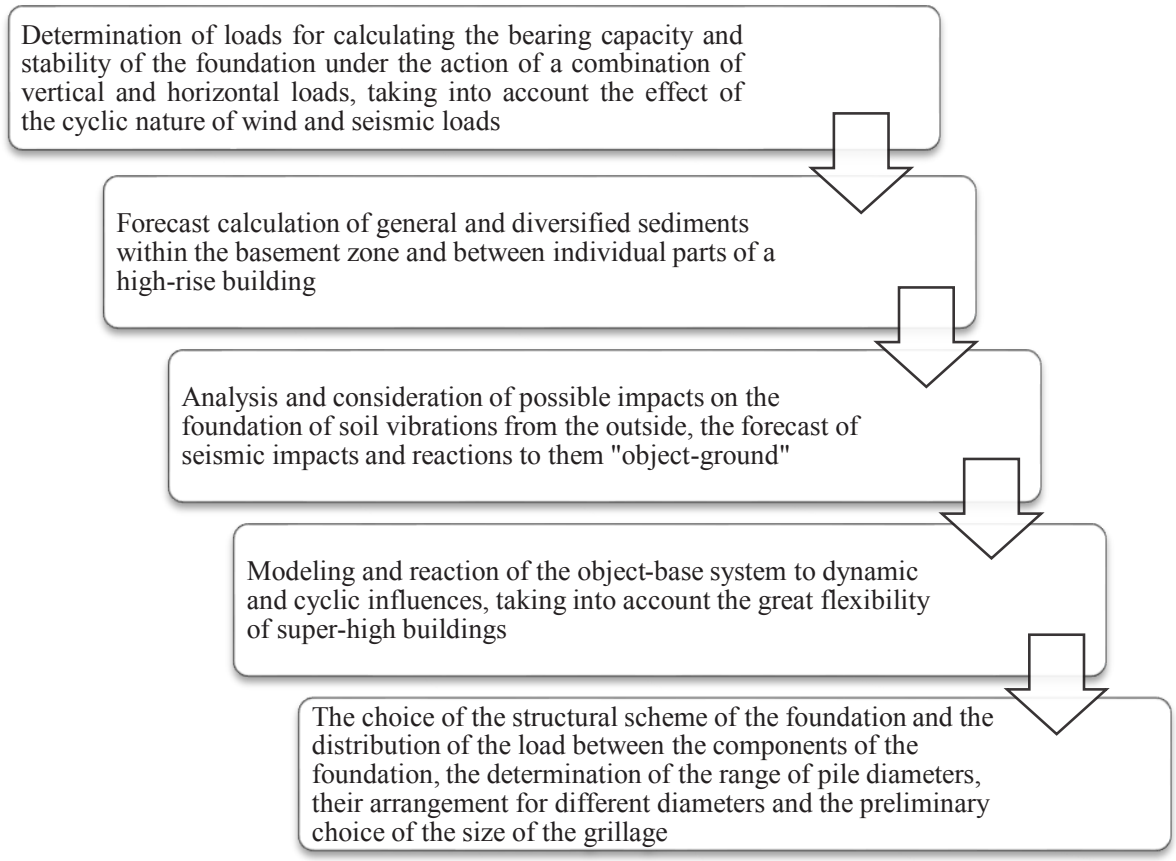

Fig. 2. The process of constructive and technological solutions and the design of foundations of highrise buildings

\subsection{Bearing structures}

Load-Bearing structures of high-rise buildings at the very beginning of the development of this type of construction were mainly made of steel. And today in buildings with a height of more than $300 \mathrm{~m}$, including "ultra-high", steel structures are used for load-bearing elements. Assembly of factory installation elements on the construction site is carried out with the help of bolted connections, which allows to increase the accuracy of installation by eliminating warpage of steel structures under the influence of high temperatures.

Steel structures are advisable to be used in seismic resistant regions, since steel, due to its plasticity, provides damping of the kinetic energy of seismic impacts. At the same time, steel structures require mandatory reliable protection against fire, since at $300^{\circ} \mathrm{C}$ the strength of steel is sharply reduced.

To increase the load-carrying capacity of columns with the restriction of the dimensions of its cross-section is possible due to the use of steel concrete. Internal walls, including staircase-elevator units (trunks), in recent years have been made, as a rule, from reinforced concrete or encased steel structures, which is dictated by considerations of fire safety.

In recent years, load-bearing structures of high-rise buildings are increasingly preferred to be made of reinforced concrete, since this material has a higher fire resistance and is cheaper, and its strength characteristics approach the strength of steel.

The center of research of prefabricated reinforced concrete frames was Japan. There since the 1970s, seismic resistant frames of high-strength concrete (classes B60-B100) have been developed and introduced into high-rise construction. Tests carried out by Japanese scientists confirmed the possibility of erecting high-rise buildings under conditions of high seismicity.

The structures of high-rise buildings are continuously being improved and are becoming increasingly diverse. In the last decade, pipe-concrete structures of reinforced concrete skeleton are actively used. Their high load-bearing capacity contributed to the revision of the 
approach developed over the past 30 years to the application in buildings above $300 \mathrm{~m}$ only of the shell structural system.

Horizontal load-bearing structures of high-rise buildings, as a rule, are of the same type and represent a rigid fireproof disc - reinforced concrete (monolithic, prefabricatedmonolithic, prefabricated) or steel-reinforced concrete.

Reinforced concrete floors are made in the form of continuous flat slabs, including prestressed, monolithic ribbed ones with main and secondary beams, monolithic caisson slabs, prefabricated and prefabricated monolithic beam or ribbed structures. At spans of up to $8 \mathrm{~m}$, non-beam ceilings made of solid monolithic plates up to a thickness of $26 \mathrm{~cm}$ are widely used.

Prefabricated cast-in-situ reinforced concrete floors of high-rise buildings have become widespread in Japan, since in this case the advantages of industrial manufacturing of the main volume of reinforced concrete are effectively used, which significantly increases the rate of installation of ceilings and preserves the positive qualities of monolithic structures.

A feature of overlapping of high-rise buildings is the fact that suspended ceilings and technological floors are used to accommodate numerous engineering systems (ventilation, heating, conditioning, electricity, etc.) and communications (computer, signal, video surveillance, automation, etc.). The total height of suspended ceilings and technological floors reaches $900 \mathrm{~mm}$, so that at a height of $3,6 \mathrm{~m}$ the height of the room is $2,7 \mathrm{~m}$. For the passage of engineering communications in solid beams of overlap, there are appropriate holes, the influence of which on the bearing capacity of beams should be taken into account in calculations .

According to the requirements of strength and fire resistance, all vertical and horizontal load-bearing structures of buildings with a height of more than $100 \mathrm{~m}$ will be made of highstrength concrete of class B60-B80 with a fire resistance rating of at least REI 240.

The structures of the coatings for the landing area for rescue helicopters should be made of the same materials and with the same fire resistance limit.

\subsection{Enclosing structures}

According to the constructive solution, the enclosing structures of high-rise buildings are designed either based on interstorey ceilings or suspended to them and performing only the function of protection from climatic, atmospheric factors and providing thermal insulation.

In modern high-rise buildings light profile systems with filling with panels made of aluminum, special glass, polymeric materials, ventilated systems finished with natural or artificial stone, decorative metal sheets, fiber-reinforced concrete screens and other materials are widely used.

Facade systems of high-rise buildings must be technological, air-and vapor-proof, fireresistant, noise-proof, durable and reliable in operation, maintainable, and also have good thermal insulation properties, low coefficient of thermal expansion and low mass.

The climatic effect on the facade systems of high-rise buildings is exerted by the wind, as well as solar radiation, torrential rains, thunderstorms and smog. Facade structures should not only withstand direct wind pressure (up to $20-25 \mathrm{~m} / \mathrm{s}$ ), but also resist tearing forces that occur when air moves along the wall and negative pressure zones appear due to turbulence.

A special place in the varieties of enclosing structures is occupied by translucent enclosing systems. They are designed in accordance with several conditions. Profiled bearing elements for increasing strength properties and durability, as a rule, are made of steel. In translucent filling, especially strong, fire-resistant, low-emission and sun-protective glasses are used. In the practice of modern high-rise construction, double skin systems with external protective screens made of especially durable glass are widely used. They allow you to make the inner glazing partially or fully openable. 


\section{Conclusions}

Each high-rise building is unique, but at the same time it allows to expand the experience of construction and operation of such buildings for further improvement. The systematization of this experience is important and can be used at the stage of developing the concept of the project and making pre-project decisions.

From the correct choice of the structural system of a high-rise building, the consumption of materials on the bearing structures and the cost of construction depends to a large extent.

Increasing the resistance of a high-rise building to wind loads can be achieved by using a rational form. As shown by numerous foreign studies and operational experience, the most suitable form for the impact of wind is the circular shape of the building. Somewhat inferior to it is an elliptical (oval) shape, and then a square one.

Load-Bearing structures of high-rise buildings distinguish high requirements for strength and deformation characteristics of materials. Traditional materials such as steel and reinforced concrete are used in combination and predetermine the development of new types of combined carrier systems in parallel with the development, research and implementation of high-strength concrete class B 100.

Requirements for facade systems designed for high-rise building construction, far exceed the requirements for the enclosing structures of conventional houses, due to the multiple increase in all types of loads - both dynamic and climatic. The facades of high-rise buildings should be air-and vapor-proof, fireproof, technological, noise-proof, durable and reliable in operation, maintainable, and also have good thermal insulation properties, low coefficient of thermal expansion and low mass.

Facade systems are constantly being improved, new technologies for fabrication and installation of structures, materials (ceramics combined with borosilicate glass, metal foam panels, nanocomposites, glass panels with a superhydrophobic self-cleaning layer, etc.) are being developed.

\section{References}

1. A. Abdelrazaq, F. Badelow, Sun-Gho-Kim, H. G.Poulos, Incheon Tower: Foundation Design in Reclamation Area. Tall Buildings 2/17, 104-109.

2. Liu Peng, Cheng Yu, Zhu Yan-Song Constructions seismic stability Structural Design of China Zun Tower. Tall Buildings 2/17, 110-119

3. V. Almazov, Ways and methods of counteracting the progressive destruction of highrise buildings. Global security, 46-49 (2006)

4. Y. Granik, A. Magay, Overview of foreign construction experience in high-altitude housing construction, Unique and special technologies in construction. 1, 20-31 (2004)

5. V. Sevostyanov, I. Mindel, B. Trifonov, Evaluation of seismic hazard for high-rise, 5662 (2006)

6. M. Shchukina, Modern high-rise construction. Monograph. - Moscow: State Unitary Enterprise "ITC Moscomarchitecture", 440 (2007)

7. T. Maklakova, N. Senin, Architectural and constructive problems of designing highrise buildings: scientific and educational material. (Moscow, 2009)

8. O. Prishchepa, A. Karavaev, A. Bushinskaya, Resilience of High-Rise RC Buildings to Dynamic Impacts. IOP Conference Series: Materials Science and Engineering, 262(1) (2017) 
9. O. Petrova, O. Lugchenko, M. Hammud, A. Nazhem, To the rationalization of the constructive solutions of the bridge supports. MATEC Web of Conferences, 106 (2017)

10. V. Shumeyko, The support systems of unique high-rise buildings. MATEC Web of Conferences, 106 (2017)

11. E. Generalova, V. Generalov, A. Kuznetsova, Innovative solutions for building envelopes of bioclimatical high-rise buildings. Vide. Tehnologija. Resursi Environment, Technology, Resources 1, 103-108 (2017)

12. Shi, S., Ren, X. Analysis of form on indoor wireless fiber network. 2nd International Conference on Artificial Intelligence, Management Science and Electronic Commerce, AIMSEC 2011 Proc. 6011402, c. 6135-6138 (2011)

13. P. Liu, C. Yin, Y. Cheng, Structural design and research of Beijing CBD Core Area Z15 Plot China Zun Tower, Building Structure, 44(24), 1-8. (2014)

14. Y. Cheng, P. Liu, D. Citerne, Y. Liu Structural parametric design applied in Beijing CBD Core Area Z15 Plot China Zun Tower, Building Structure, 44(24), 9-14 (2014)

15. P. Liu, C. Yin, K. Lee, and et al. Structural system design and study of Tianjin Goldin 117 Mega Tower, Building Structure, 42(3), 1-9. ASCE "Seismic rehabilitation of existing buildings" ASCE/SEI 41-06 (2007)

16. M. Kwok, C. Gibbons, J. Tsui, P. Liu, Y. Wang, The Structural Design of Mega Tower, China World Trade Center Phase 3, Beijing China. Paper presented at: Tall Buildings From Engineering to Sustainability, Proc. of 6th Inter. Conf. On Tall Buildings, Hong Kong, 396-402 (2005)

17. P. Xu, Structural Design of Complex Tall Buildings, Beijing: China Architecture \& Building Press (2005)

18. Ministry of Housing and Urban-Rural Development of the People's Republic of China Technical review requirement on seismic design of code-exceeding tall building structures. Jianzhi, 109. (2010)

19. M. Mikhailova, V. Dalinchuk, A. Bushmanova, L. Dobrogorskaya, Construction of unique buildings and structures. 10 (49), 59-74 (2016)

20. URL: http://www.antula.ru/site-rielter 271.htm (05.03.2017)

21. V. Generalov, E. Generalova, High-rise residential buildings and complexes (Samara, 2013) 